\title{
Anatomical assessment of the endoscopic endonasal approach for the treatment of paraclinoid aneurysms
}

\author{
Ali Tayebi Meybodi, MD, Leandro Borba Moreira, MD, Andrew S. Little, MD, \\ Michael T. Lawton, MD, and Mark C. Preul, MD \\ Department of Neurosurgery, Barrow Neurological Institute, St. Joseph's Hospital and Medical Center, Phoenix, Arizona
}

OBJECTIVE Endoscopic endonasal approaches (EEAs) are increasingly being incorporated into the neurosurgeon's armamentarium for treatment of various pathologies, including paraclinoid aneurysms. However, few anatomical assessments have been performed on the use of EEA for this purpose. The aim of the present study was to provide a comprehensive anatomical assessment of the EEA for the treatment of paraclinoid aneurysms.

METHODS Five cadaveric heads underwent an endonasal transplanum-transtuberculum approach to expose the paraclinoid area. The feasibility of obtaining proximal and distal internal carotid artery (ICA) control as well as the topographic location of the origin of the ophthalmic artery (OphA) relative to dural landmarks were assessed. Limitations of the EEA in exposing the supraclinoid ICA were also recorded to identify favorable paraclinoid ICA aneurysm projections for EEA.

RESULTS The extracavernous paraclival and clinoidal ICAs were favorable segments for establishing proximal control. Clipping the extracavernous ICA risked injury to the trigeminal and abducens nerves, whereas clipping the clinoidal segment put the oculomotor nerve at risk. The OphA origin was found within $4 \mathrm{~mm}$ of the medial opticocarotid point on a line connecting the midtubercular recess point to the medial vertex of the lateral opticocarotid recess. An average 7.2-mm length of the supraclinoid ICA could be safely clipped for distal control. Assessments showed that small superiorly or medially projecting aneurysms were favorable candidates for clipping via EEA.

CONCLUSIONS When used for paraclinoid aneurysms, the EEA carries certain risks to adjacent neurovascular structures during proximal control, dural opening, and distal control. While some authors have promoted this approach as feasible, this work demonstrates that it has significant limitations and may only be appropriate in highly selected cases that are not amenable to coiling or clipping. Further clinical experience with this approach helps to delineate its risks and benefits.

https://thejns.org/doi/abs/10.3171/2018.6.JNS18800

KEYWORDS aneurysm surgery; carotid cave; diaphragma sellae; paraclinoid aneurysms; pituitary transposition; ophthalmic artery; superior hypophyseal artery; transplanum-transtuberculum approach; vascular disorders; anatomy; surgical technique

B URIED under critical neurovascular structures, paraclinoid aneurysms are among the most challenging vascular lesions a neurosurgeon can encounter. The unique anatomy of this area renders limited surgical access to the origin of the ophthalmic artery (OphA), the superior hypophyseal artery (SHA), the carotid cave, and the aneurysm. These aneurysms may assume different projections, necessitating a versatile surgical strategy. ${ }^{4,18}$ The technical difficulties associated with open surgery for the treatment of paraclinoid aneurysms have caused the complication and aneurysm remnant/recurrence rates to remain relatively high in comparison with aneurysms in other locations. ${ }^{3,6,44}$ Perhaps these are the main reasons for the relative prevalence of endovascular techniques in the treatment of these difficult lesions. ${ }^{8,31,35,36}$ However, clipping continues to be a popular choice due to its durability and efficacy compared with endovascular techniques., $17,29,43$

Meanwhile, the endoscopic endonasal approaches (EEAs) have been increasing in popularity for various lesions of the skull base., ${ }^{1,24,33}$ As such, the topographic proximity of the paraclinoid internal carotid artery (ICA) to the midline raises the important question as to whether

ABBREVIATIONS DDR = distal dural ring; EEA = endoscopic endonasal approach; ICA = internal carotid artery; $L O C R=$ lateral opticocarotid recess; OphA = ophthalmic artery; PDR = proximal dural ring; SHA = superior hypophyseal artery.

SUBMITTED March 22, 2018. ACCEPTED June 27, 2018.

INCLUDE WHEN CITING Published online December 21, 2018; DOI: 10.3171/2018.6.JNS18800. 
paraclinoid ICA aneurysms are amenable substrates for EEA. Several case reports, review articles, and anatomical studies exist on the treatment of paraclinoid aneurysms through an EEA. 5,11-14,20,28,37,39,42 However, there is reluctance among skull base surgeons to treat intracranial aneurysms using an EEA for several reasons. First, compared with other pathologies (such as tumors), aneurysm surgery requires maximal control over multiple parameters, such as proximal and distal vascular control, control over the periphery of the aneurysm neck, and protection of perforating vessels; hence, the experience and team collaboration required to perform endoscopic aneurysm surgery should be at the highest level possible, which is not available at many centers. Furthermore, to date, the details of surgically relevant anatomical features of endoscopic aneurysm surgery have not been completely delineated.

In this study, we sought to address the last aforementioned issue by performing an anatomical assessment of the EEA for the treatment of paraclinoid aneurysms. Specifically, we investigated and considered the surgical anatomical parameters, including localization of the OphA before dural opening, safe dural opening, proximal and distal vascular control, and potential limitations of the EEA for the treatment of paraclinoid aneurysms.

\section{Methods}

\section{Expanded Transnasal Transplanum-Transtuberculum Approach}

Five cadaveric heads (10 sides) were prepared for EEA using an alcohol-based embalming formula. The arteries and veins were perfused with red and blue silicone, respectively. An expanded transplanum-transtuberculum EEA was performed using a surgical endoscope system (Karl Storz) with $0^{\circ}$ and $30^{\circ}$ rigid endoscopes. Bilateral middle and superior turbinectomies, posterior ethmoidectomies, and posterior nasal septectomy were performed. A large sphenoidotomy was then completed to expose the sellar and parasellar regions bilaterally. Using an endoscopic high-speed drill system (Medtronic), the lacerum and paraclival segments of the ICA were exposed using the guides of the pterygoclival ligament and the vidian nerve (Fig. 1A). ${ }^{23,40}$ Next, a wide exposure of the skull base dura was performed. The sagittal extent of bone removal extended from the posterior end of the cribriform plate to the anterior sellar region. The coronal extent of bone removal included bilateral optic canals, parasellar ICAs, region of the superior orbital fissure, and posteromedial orbital walls (Fig. 1A and B).

\section{Localization of the OphA Origin}

To localize the origin of OphA relative to dural landmarks, spatial coordinates of 4 reference points were recorded using a frameless stereotactic navigation system (StealthStation TREON Plus, Medtronic). To define these points, a brief description is required. According to Peris-Celda et al., the tubercular recess is defined as "the horizontal depression in the [sphenoid] sinus wall between the sella inferiorly and the planum superiorly." ${ }^{2}$ When followed laterally toward the junction of the optic nerve and ICA, the tubercular recess assumes the shape of a triangular depression (lateral tubercular recess) with its vertex pointed medially and the base abutted by the junction of the optic nerve and ICA (Fig. 1B). The descending arm of this triangle reaches the superior-most point along the junction of the sellar prominence with the carotid artery prominence, referred to as the caroticosellar point, ${ }^{32}$ which is close to the anteromedial aspect of the proximal dural ring (PDR) ${ }^{26}$ The ascending arm reaches the medial junction between the optic nerve and the carotid artery, i.e., the medial opticocarotid point (Fig. 1B). ${ }^{32}$ The reference points used were the 1) midtubercular recess point, 2) medial opticocarotid point, 3) caroticosellar point,,$^{32}$ and 4) medial vertex of the lateral opticocarotid recess (LOCR) (Fig. 1C). Following dural opening, the distances between the OphA origin and these reference points were calculated (Table 1; see Identification of the OphA and Distal Vascular Control below).

\section{Assessment of Proximal Control}

Feasibility of proximal control was assessed at 2 segments of the ICA: the extracavernous paraclival and clinoidal segments (Fig. 1B). Bone was completely drilled off the medial, anterior, and lateral surfaces of the extracavernous paraclival ICA (i.e., up to the level of the attachment of the petrolingual ligament to the lingular process of the sphenoid bone) $)^{26}$ to prepare the exposure area for accommodating an aneurysm clip (Fig. 1A and D). Various clip configurations were tested to assess the feasibility of obtaining proximal control on the paraclival ICA. Also, adjacent anatomical structures at risk during application of the clip were recorded.

The feasibility of obtaining proximal control was also assessed for the clinoidal ICA. The clinoidal ICA is bounded between the PDR and distal dural ring (DDR) (Fig. 1C). From an endonasal perspective, the PDR roughly approximates a line passing through the anteroinferior side of the LOCR toward the region of the middle clinoid process (usually within $4 \mathrm{~mm}$ below the caroticosellar point; ${ }^{32}$ Fig. 1C). To expose the clinoidal ICA, a dural incision was started from the caroticosellar point (approximate location of the PDR) and continued superomedially between the ICA and the superolateral contour of the pituitary. On reaching the lateral tubercular recess, the dural cut turned laterally and extended along the inferior border of the DDR (approximated by a line connecting the medial vertex of the LOCR and the medial opticocarotid point) to reach the medial vertex of the LOCR. The cut then turned inferiorly on the dural covering of the lateral aspect of the ICA (down to the level of the PDR) to create a dural flap turned inferiorly (Fig. 1E). The feasibility of controlling the clinoidal ICA was tested by trying various clip types (Fig. 1F). Adjacent structures at risk during clipping were also recorded. The available length of the clinoidal ICA (distance between the PDR and DDR) for clipping was measured using the navigation system.

\section{Dural Opening}

A tailored dural incision was used to minimize the risk of neurovascular injury, including injury to the origin of 

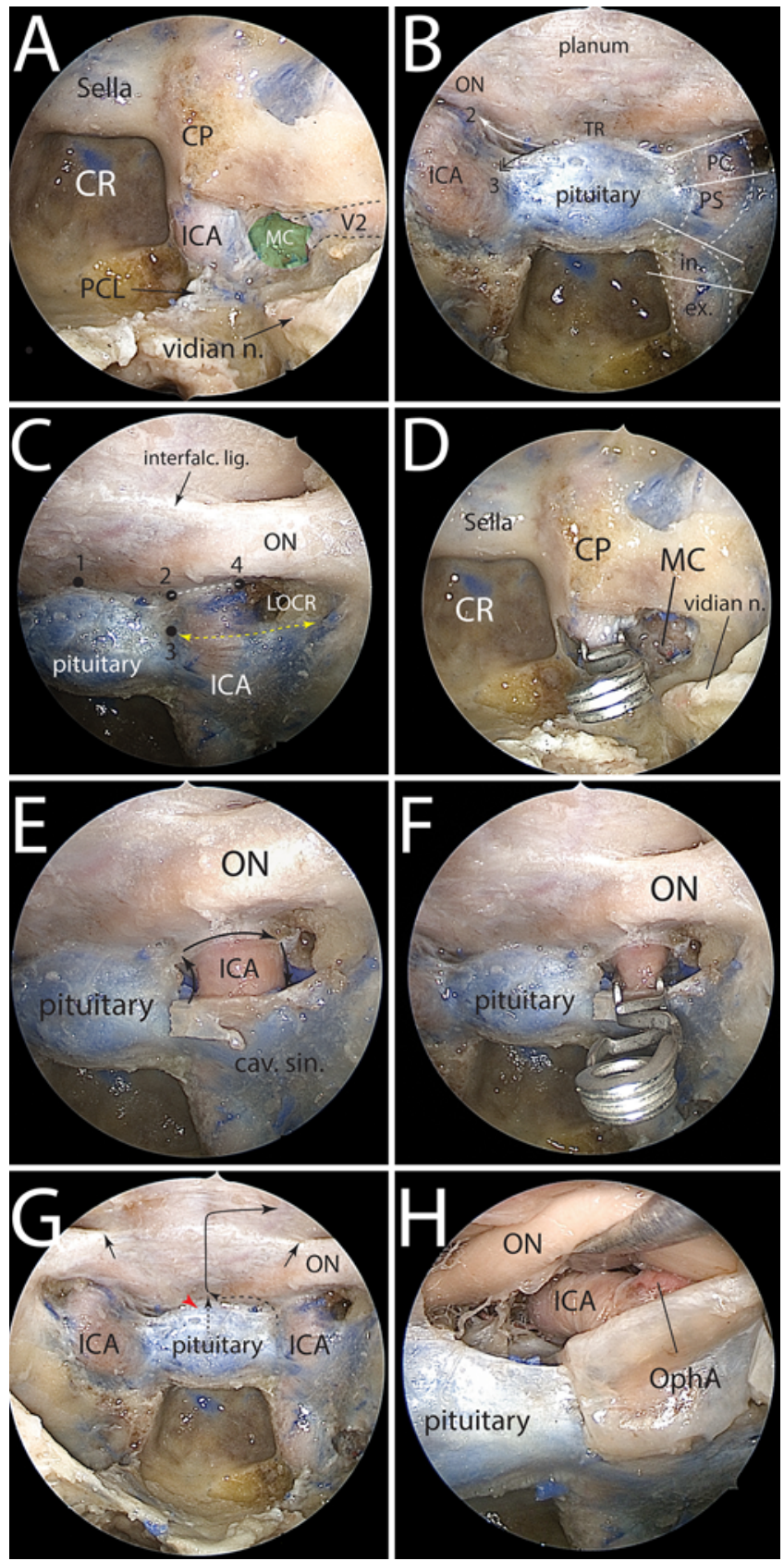

the OphA (Fig. 1G). The incision was essentially similar to that suggested by Abhinav et al. for exposing the intracanalicular part of the optic nerve. ${ }^{1}$ The dural incision started at the lateral tubercular recess (at the superomedial corner of the trap-door dural cut placed for controlling the clinoidal ICA). After crossing the superior intercavernous sinus, the incision sharply turned medially toward the midtubercular recess. Upon reaching the midline, the incision was continued toward the planum sphenoidale. After passing anterior to the interfalciform ligament, ${ }^{27}$ the cut turned laterally to continue parallel and anterior to the optic canal. The created dural flap was then turned inferiorly to expose the suprasellar paraclinoid area (Fig. 1H).
FIG. 1. Stepwise depiction of the EEA for exposure of the paraclinoid region. A: Exposure of the left paraclival ICA using the vidian nerve (n.) and the pterygoclival ligament (PCL) as anatomical landmarks. The pterygoclival ligament is a thick, fibrous tissue running between the body of the sphenoid bone and medial pterygoid process to reach the medial aspect of the lacerum segment of the ICA. The ICA is prepared for proximal clipping by drilling bone on its lateral, anterior, and medial aspects. On the lateral aspect of the ICA, there is a quadrangular space (i.e., the lingular recess), drilling of which leads to Meckel's cave (MC). In order to protect the abducens nerve running on the superior aspect of this space, drilling should be limited superiorly to the level of the maxillary division (V2) of the trigeminal nerve. B: Dural exposure extending from the planum sphenoidale to the anterior sellar region in the sagittal plane and extending laterally to the optic canals and parasellar carotid arteries. Dashed lines designate the approximate course of the paraclival (including the extracavernous [ex.] and intracavernous [in.] parts), parasellar (PS), and paraclinoid (PC) segments of the ICA separated by solid white lines. The lateral tubercular recess (TR) is a triangle-shaped area on the lateral end of the tubercular recess reaching medial to the optic nerve and ICA (shown on the right side). The corner of this triangular area faces medially; the upper arm (white arrow) reaches the medial opticocarotid point (point 2), and the lower arm (double black arrow) reaches the caroticosellar point (point 3). C: Dural reference points: 1 = midtubercular recess point; 2 = medial opticocarotid point; 3 = caroticosellar point; $4=$ medial vertex of the LOCR. The white dashed line shows the approximate level of the DDR, and the yellow dashed doublearrowed line shows the approximate level of the PDR. D: Proximal control obtained on the extracavernous paraclival ICA. E: Exposure of the clinoidal ICA using 3 consecutive dural cuts (black arrows) starting from the caroticosellar point reaching the medial opticocarotid point, and then continuing inferior to the DDR to reach the medial vertex of the lateral opticocarotid recess, and finally descending on the lateral aspect of the clinoidal ICA. F: Proximal control on the clinoidal ICA. G: Dural incision to expose the supraclinoid ICA. The dural incision could be started either on the lateral tubercular recess or in the midline (dashed arrowsboth crossing the superior intercavernous sinus [red arrowhead]) to reach the tubercular recess. Next, the dural incision is continued in the midline to reach planum sphenoidale and then turns laterally to reach the region of the optic canal. Small black arrows show the interfalciform ligament (interfalc. lig.). $\mathrm{H}$ : The supraclinoid ICA is exposed by reflecting the dural flap. All views were obtained using a $0^{\circ}$ endoscope. cav. sin. $=$ cavernous sinus; $\mathrm{CP}=$ carotid protuberance; $\mathrm{CR}=$ clival recess; $\mathrm{ON}=$ optic nerve. Copyright Mark Preul. Published with permission. Figure is available in color online only.

\section{Identification of the OphA and Distal Vascular Control}

Using a 4-handed surgical technique, ${ }^{12}$ the supraclinoid ICA and the origin and preforaminal course of the OphA were identified (Fig. 1H). The spatial coordinates of the OphA origin were recorded. Using mathematical methods, the distance between the OphA origin and reference points was calculated. Next, the feasibility of clipping the ICA at the distal-most accessible point to the origin of OphA was assessed (Fig. 2). Various clip configurations were tested to find the optimal clip shape. The necessary maneuvers to safely place the clip while sparing the perforators were recorded. Of note, "safe" maneuvers in this paper are defined as those that do not incur gross damage to the adjacent neural or vascular structures, as true safety of a maneuver cannot be assessed in a cadaveric study. Also, the maximum possible clipping length of the supraclinoid ICA was calculated using the recorded spatial coordinates of the clip application point and the emerging point of the ICA from the DDR. 
TABLE 1. Measurements performed to localize the origin of the OphA to 4 dural reference points

\begin{tabular}{lc}
\hline \multicolumn{1}{c}{ Measurement } & $\begin{array}{c}\text { Distance to OphA } \\
\text { Origin }(\mathrm{mm})\end{array}$ \\
\hline OphA origin-point 1 & $9.1 \pm 0.7$ \\
\hline OphA origin-point 2 & $3.5 \pm 1.5$ \\
\hline OphA origin-point 3 & $6.3 \pm 1.5$ \\
\hline OphA origin-point 4 & $4.8 \pm 1.9$ \\
\hline Point 1-point 4 (length of opticotubercular line) & $13.2 \pm 1.7$ \\
\hline Sum of OphA origin distance to points 1 \& 4 & $13.9 \pm 1.6$ \\
\hline
\end{tabular}

Point 1 = midtubercular recess point; point 2 = medial opticocarotid point; point $3=$ caroticosellar point; point $4=$ medial vertex of the LOCR

Values are presented as the mean \pm standard deviation.

\section{Results}

The sphenoid sinus was well pneumatized in all specimens (sellar type). Using the described technique, the paraclival, clinoidal, and supraclinoidal segments of the ICA, as well as the OphA, were safely exposed in all specimens. Table 1 lists the average distance from the origin of the OphA to the 4 dural reference points. In all specimens, the sum of the distance between the OphA origin and points 1 and 4 (Fig. 1C) was almost equal ( $<2$-mm difference) to the distance between points 1 and 4 , meaning that the OphA origin was located on or very close to the opticotubercular line (the line passing through the midtubercular recess point [point 1] and the medial vertex of the LOCR [point 4]). The OphA origin was close (within $4 \mathrm{~mm}$ ) to the medial opticocarotid point (Table 1, Fig. 3).

\section{Proximal Control}

The paraclival ICA was a favorable point for obtaining proximal control on the ICA. It was necessary to drill the bone off its medial, anterior, and lateral surfaces in order to place the clip. Lateral drilling included part of the bone of the quadrangular area lateral to the paraclival ICA $^{21}$ (i.e., the lingular recess ${ }^{26}$ ). Straight aneurysm clips were optimal for this purpose. With extensive drilling of the lingular recess, the outer blade of the clip could reach Meckel's cave during application. To avoid injury to the abducens nerve during exposure of the paraclival ICA and clip application, the drilling did not extend superior to the level of the maxillary nerve (Fig. 1A and D).

A mean length of $6.2 \pm 1.2 \mathrm{~mm}$ of the clinoidal ICA could be exposed for clip application (range 5.0-8.4 mm). A straight or a curved clip (with the tips directed downward) was used to establish proximal control at the clinoidal ICA (Fig. 1D). Whereas the pituitary gland was visible on the medial side of the ICA and could be easily protected during application of the clip, care was needed to protect the oculomotor nerve (coursing under the PDR) from the lateral clip blade (Fig. 4).

\section{Exposure of the OphA and Distal Control}

Using the tailored dural incision, we were able to successfully avoid injury to the neurovascular structures in all specimens. Alternatively, the dural incision could be
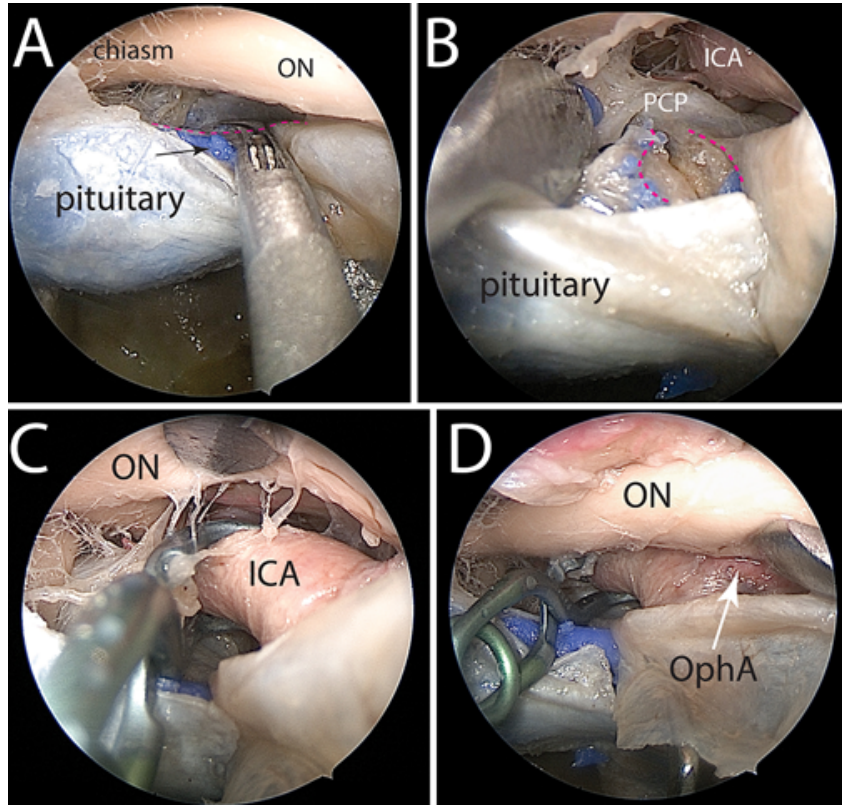

FIG. 2. A and B: Enhancing exposure of the supraclinoid ICA by cutting the superior intercavernous sinus (small black arrow) and the diaphragma sellae (red dashed line). This cut (red dashed lines in B) could reach the posterior clinoid process (PCP) posteriorly to allow medial mobilization of the pituitary. C and D: Distal control of the supraclinoid ICA after incising the diaphragma sellae. Note the superior retraction of the optic nerve (ON) necessary to apply the clip. The white arrow (D) indicates the origin of the OphA. All views were obtained using a $30^{\circ}$ endoscope. Copyright Mark Preul. Published with permission. Figure is available in color online only.

started just inferior to the superior intercavernous sinus at the midline (Fig. 1G).

The OphA originated from the supraclinoid ICA in all specimens. The OphA originated from the superomedial aspect of the ICA in 8 of 10 specimens and from the superior aspect of the ICA in the remaining 2 specimens. In all specimens, some degree of optic nerve elevation was necessary to allow optimal visualization of the distal segments of the supraclinoid ICA (Fig. 2). Using this method, visualization of the medial and superior aspects of the supraclinoid ICA was possible in all specimens. However, visualization of the lateral aspect of the supraclinoid ICA was significantly limited and required excessive superior retraction of the optic nerve. Using a 4-handed technique, following gentle elevation of the optic nerve, an aneurysm clip could be applied to the supraclinoid ICA. The optimal clip for this purpose was a right-angle clip with the tips directed laterally (Fig. 2). Importantly, incising the diaphragma sellae along the medial aspect of the DDR increased the available space and improved the safety of passing a clip onto the distal ICA. This cut increased the mobility of the ICA and enabled gentle manipulation of the pituitary to allow clip application (Fig. 2). The clip could be safely placed distal to the origin of the SHA (i.e., between the SHA and posterior communicating artery) in 5 of 10 specimens. In the remaining specimens, a short, nonredundant SHA did not allow the clip to be safely passed along the ICA distal to the origin of SHA. 

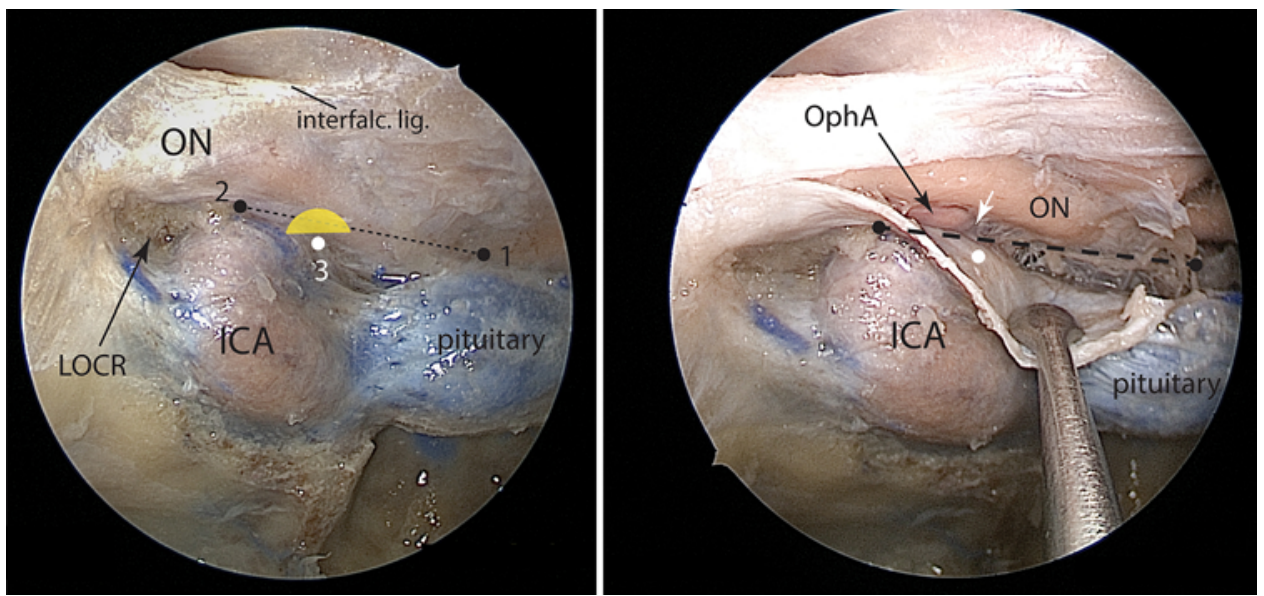

FIG. 3. Opticotubercular line shown on the right parasellar area. Left: The opticotubercular line runs from the midtubercular recess point (point 1) to the medial vertex of the LOCR (point 2). The OphA origin was found on this line (or close to it) within $4 \mathrm{~mm}$ of the medial opticocarotid point (point 3; yellow shaded area). Right: The dura is opened and the origin of the OphA (white arrow) is found. The opticotubercular line is drawn, and the OphA origin is shown to be very close to this line near the medial opticocarotid point (white dot). All views were taken with a $30^{\circ}$ endoscope. Copyright Mark Preul. Published with permission. Figure is available in color online only.

The mean length of the supraclinoid ICA at the point of the distal clip was $7.2 \pm 1.7 \mathrm{~mm}$.

\section{Discussion}

We performed a comprehensive assessment of the EEA for the clipping of paraclinoid ICA aneurysms. Anatomical assessment of the EEA to delineate its assets and liabilities for aneurysm surgery is critically important, as aneurysm surgery requires the ultimate control in neurosurgery. ${ }^{12}$ Such assessment is incomplete without providing insight into specific aspects of aneurysm surgery, including proximal and distal vascular control, and the risks and benefits of exposing certain aneurysm projections via an EEA. We performed an extensive search of the literature in PubMed using various combinations of the keywords "endoscopic," "endonasal," "transnasal," "transclival," "transsphenoid," "aneurysm," and "clipping." We found 25 studies on the subject of endoscopic endonasal aneurysm surgery, 10 of which were on paraclinoid aneurysms, , $, 11-14,20,28,37,39,42$ including 4 literature reviews/perspectives, ${ }^{11,14,37,42} 3$ case reports or case series, ${ }^{12,13,20}$ and 3 anatomical studies..$^{5,28,39}$ Lai et al. performed an anatomical study on the EEA to the paraclinoid region. ${ }^{28}$ They assessed operative depth and dimensions of the exposed area. Although the authors assessed clipping feasibility, they did not evaluate different clip configurations or risks associated with clipping each segment or branch of the paraclinoid arteries. Szentirmai
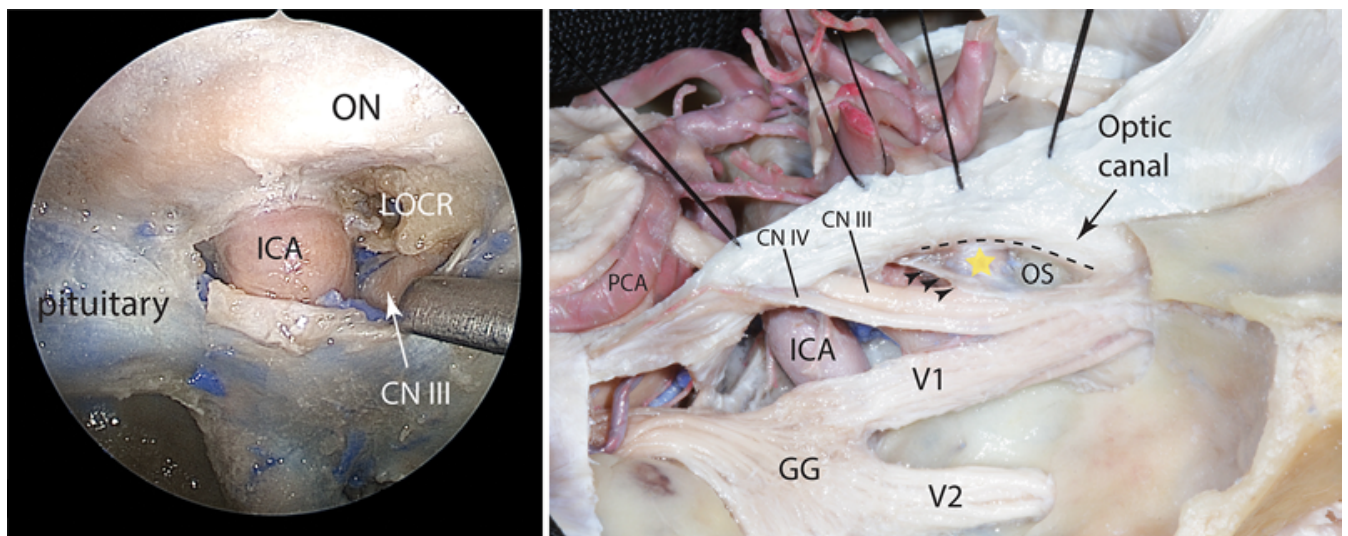

FIG. 4. Close relationship between the oculomotor nerve and the clinoidal ICA. Left: Endoscopic endonasal view of the left parasellar area ( $30^{\circ}$ endoscope) shows that violation of the PDR is easily possible; hence clipping the clinoidal ICA may pose risk to the adjacent oculomotor nerve running immediately inferior to the PDR. Right: Cavernous sinus dissection on the right side showing the close relationship between the PDR (black arrowheads) and the underlying oculomotor nerve. The dashed line shows the DDR. The yellow star designates the clinoidal ICA. Note that the anterior clinoid process has been removed. $\mathrm{CN}=\mathrm{cranial}$ nerve; $G G=$ Gasserian ganglion; $O S=$ optic strut; $P C A=$ posterior cerebral artery. Copyright Mark Preul. Published with permission. Figure is available in color online only. 
et al. measured the craniectomy size and operative corridor angles to the paraclinoid region, and concluded, "Using this approach, medially located ophthalmic or hypophyseal artery aneurysms were very reasonable candidates for endonasal clip ligation." 39 Di Somma et al. measured operative depth and angle, as well as craniectomy size, to the parasellar region to assess the anatomical feasibility of clipping various aneurysms. ${ }^{5}$ None of the aforementioned studies assessed the relevant surgical anatomical variables, such as proximal and distal vascular control or the impact of clipping on adjacent structures. They also did not assess or discuss safe dural opening specific to paraclinoid aneurysm surgery. Therefore, the present study provides some data not presented in previous publications.

\section{Endonasal Exposure}

The transplanum-transtuberculum approach through bilateral sphenoidotomies is the suggested endoscopic skull base approach to reach the paraclinoid area, as it has been used in previous reports. ${ }^{12,13,20}$ However, the endonasal exposure could be tailored to specific patient anatomy/ pathology and may be performed in a more limited fashion, such as through a unilateral turbinectomy or lateralization of the middle turbinate for a small aneurysm.

\section{Proximal Vascular Control}

Obtaining proximal vascular control through an EEA could be challenging. ${ }^{13}$ Proximal control for paraclinoid ICA aneurysms can be obtained at the cervical ICA. However, due to the endonasal instrumentation, the clean field of cervical exposure might be at an increased risk for infection. Other potential targets for proximal ICA control include the paraclival segment (including extracavernous and intracavernous parts ${ }^{26}$ ) and the clinoidal ICA segment (Fig. 1B). ${ }^{120,42}$ Some authors have stated that opening the medial compartment of the cavernous sinus does not carry a significant risk for the nerves traveling inside the sinus. ${ }^{42}$ However, we think that the intimate relationship between the abducens nerve and the cavernous ICA puts this nerve at risk during clip application on the cavernous ICA. ${ }^{34}$

The extracavernous paraclival ICA is located above the foramen lacerum and ends just before the ICA enters the cavernous sinus (Fig. 1B). Therefore, exposure of this segment is at less risk for venous bleeding. However, we found that in order to prepare this ICA segment for clipping, extensive bone drilling is needed. This drilling includes part of the quadrangular space located lateral to the ICA, which is referred to as the "front door to Meckel's cave" by Kassam et al. ${ }^{21}$ Therefore, the trigeminal nerve at the area of Meckel's cave might be injured by the clip blade lateral to the ICA (Fig. 1D). Limited drilling lateral to the ICA could prevent this risk. Also, there is some risk to the abducens nerve while drilling the quadrangular space. To avoid this risk, we stayed inferior to the axial level of the maxillary nerve as recommended by Kassam et al. (Fig. 1A). ${ }^{21}$

Another potential location for obtaining proximal ICA control is the clinoidal segment. Exposure of the clinoidal ICA carries exquisite risk of arterial injury because the ICA is only covered with the dura without a venous cushion like the cavernous segment. Extensive bone removal from the cavernous sinus, medial opticocarotid recess, and middle clinoid area is required to enable efficient exposure of the clinoidal ICA..$^{10,12}$ There is only a thin clinoid venous plexus around this segment of the ICA (also known as the carotid collar). ${ }^{16}$ This exposure requires placing dural incisions around the underlying ICA, which could be extremely dangerous, especially when complicated by venous injury from the carotid collar or the inferiorly located cavernous sinus (Fig. 1E). Nevertheless, once exposed, the clinoidal ICA can be clipped relatively easily. However, the oculomotor nerve is at risk because it runs just inferior to the PDR. As the PDR is thin, violation of this membrane and entry to the cavernous sinus is highly probable during exposure of the clinoidal ICA (Fig. 4).

Whereas all our specimens had a sellar-type sphenoid sinus, a less pneumatized sphenoid sinus may create a challenge for exposing both the ICA and the sellar and parasellar regions, especially in the case of an aneurysm, because the risk of aneurysm rupture may increase with the need to drill more bone in its vicinity.

\section{Dural Opening and Exposure of the OphA}

Having a see-through image of the origin of the OphA before dural opening is of utmost importance to avoid vascular injury. Several authors have recommended being cautious while opening the dura at the vicinity of the optic nerve during EEA without providing practical landmarks to safely expose the OphA.1,15,45 According to our results, the opticotubercular line (passing through the medial vertex of the LOCR and midtubercular recess point) was a useful guide in localizing the OphA origin. The origin of the OphA was usually found on this line within $4 \mathrm{~mm}$ of the medial opticocarotid point (Fig. 3). Therefore, any dural incision should avoid this projected point of the OphA origin on the dura (Fig. 1G). The dural incision that we used created a nice dural flap that could optimally expose the OphA and adjacent structures while avoiding the optic nerve. Obviously, an OphA originating aberrantly from the ICA (e.g., from the cavernous ICA) cannot be localized using this method. Also, paraclinoid aneurysms, especially when large, may alter this topography. In such situations, preoperative assessment of the course of the OphA and its relationship to adjacent structures is critical. Also, the intraoperative use of a Doppler probe could help with localization of the origin and course of the OphA, ${ }^{1}$ although this might be of less use in aneurysm cases. It is noteworthy that, depending on the aneurysm size, morphology, and location, a more extensive dural opening toward the cavernous ICA with or without pituitary transposition may be necessary. ${ }^{13,20}$ As the SHA origin is distal to the OphA origin, the same dural incision is potentially applicable to SHA aneurysms, although the opticotubercular line cannot be used to estimate the origin of this artery.

\section{Distal ICA Control}

Distal control is essential, yet very challenging during EEA, especially with ruptured aneurysms. ${ }^{12}$ An extensive exposure which may include generous bone removal around the optic canal or even a concomitant transcranial exposure is usually required. ${ }^{12,13}$ We were able to place a right-angle aneurysm clip on the distal ICA either proximal or distal to the origin of SHA (average ICA clipping 
length $7.2 \mathrm{~mm}$ ). Mobilizing the ICA through opening the diaphragma sellae and creating space superior to the ICA via superior retraction of the optic nerve were necessary for maximizing exposure during clip placement. Despite these maneuvers, safely placing the distal ICA clip was challenging in all specimens as the tips of the clip could not be easily visualized at the lateral aspect of the ICA. This challenge may be even greater when a large medially or superiorly projecting aneurysm limits distal ICA visualization. Also, the course and origin of SHA may hinder efficient clip application. A short, taut, nonredundant SHA originating close to the OphA may not allow clip application beyond the SHA origin. Unfortunately, this parameter is not comprehensible before surgery due to the small size of the SHA and can only be appreciated after dural opening. Overall, the drawback of suboptimal distal control should be considered in cases of paraclinoid aneurysms that are selected for treatment via an EEA, especially with larger lesions.

\section{Identification of Potential Favorable Paraclinoid ICA Aneurysms for EEA \\ General Considerations}

EEA for aneurysm treatment is not a minimally invasive approach. Some technical features of EEA have caused many to be skeptical about the use of this method for aneurysm treatment. ${ }^{9,25,38}$ With the deep, narrow corridor of EEA, achieving team proficiency in EEA is both of paramount importance and difficult. Additionally, despite marked reduction in CSF leakage rates after the introduction of the nasoseptal flap, ${ }^{22,30} \mathrm{CSF}$ leakage and meningitis could still cause major problems after EEA.

Strict adherence to the principles of aneurysm surgery (e.g., efficient proximal and distal control) is crucial during EEA. If these principles cannot be followed in the individual case, EEA is contraindicated. ${ }^{20}$ Extensive anatomical knowledge and meticulous technique are essential. The operating team should have extensive experience with both the treatment of aneurysms and EEA and should also be comfortable with using the 4-handed endoscopic technique. ${ }^{12,13,20,28}$ The surgical team should also be especially experienced in handling extreme situations such as an intraoperative aneurysm rupture. ${ }^{19,41}$ Specific endoneurosurgical instruments should be designed and manufactured for aneurysm surgery. ${ }^{12}$

The potential of aneurysm recurrence should be considered before deciding to proceed with EEA. Complex aneurysms have a higher risk of having a remnant or recurring after surgery. It has been reported that the second EEA is more difficult, as the surgeon has to deal with adhesions of the aneurysm and clip to adjacent structures with a high risk of complications.$^{13}$ Also, should a second (transcranial) surgery become necessary, it is extremely difficult to remove endonasally placed clips through a transcranial exposure. Therefore, simple small-neck aneurysms with low risk for recurrence are probably more favorable for EEA. ${ }^{12}$

\section{Specific Considerations Regarding Paraclinoid Aneurysms}

Lai et al. showed that exposure of ICA branches posterior to the coronal plane of the pituitary stalk is significantly limited compared with those located anterior to the stalk..$^{28}$ Concordantly, our results show that only an average of $7.2 \mathrm{~mm}$ of the supraclinoid ICA could be efficiently controlled with clips (i.e., distal control). Therefore, paraclinoid aneurysms located distal to this clipping point may not be favorable for EEA.

Regarding aneurysm projection, laterally projecting OphA aneurysms and those arising from the posterior aspect of the clinoidal ICA may not be suitable for EEA as their visualization is extremely limited during EEA. Superiorly projecting aneurysms of the OphA (within 7.2 $\mathrm{mm}$ of the DDR) may be favorable candidates for EEA because they are readily exposed on dural opening and the neck could be dissected and clipped without the need for extensive optic nerve manipulation (these aneurysms have already displaced the optic nerve superiorly). ${ }^{4}$ Medially projecting aneurysms may also be favorable candidates as long as they are not so large that they hinder the visualization and control of the aneurysm neck and the distal ICA. In fact, all previously reported aneurysms treated via EEA had a component of medial projection (i.e., superomedial, inferomedial, or pure medial). ${ }^{12,13,20}$ Obviously, nonruptured aneurysms are safer to expose and clip than ruptured lesions.

\section{Study Limitations}

The main limitation of the present work is the absence of the target pathology (i.e., paraclinoid aneurysms) in cadaveric specimens. This may limit the applicability of our findings in real surgical cases. Also, anatomical studies cannot assess clinical complications, such as visual sequelae or hypopituitarism. However, our results provide a deeper insight into the advantages and disadvantages of the EEA for paraclinoid aneurysm surgery.

\section{Conclusions}

EEA has certain risks and limitations for the treatment of paraclinoid aneurysms, including difficulties with proximal and distal control, limited maneuverability on the paraclinoid structures, and potential need for excessive retraction of the optic nerve to dissect the aneurysm neck and visualize distal ICA. These findings show that the EEA may not be optimal for most paraclinoid aneurysms. Nevertheless, a subset of paraclinoid aneurysms may be favorable candidates for an EEA strategy. These include small superiorly or medially projecting aneurysms within $7.2 \mathrm{~mm}$ of the DDR. Further clinical experience would help to delineate the actual role of EEA in paraclinoid aneurysm treatment and delineate its true risks and benefits.

\section{Acknowledgments}

This study was supported by Barrow Neurological Foundation support to Dr. Tayebi Meybodi, and from the Newsome Chair in Neurosurgery Research held by Dr. Preul.

\section{References}

1. Abhinav K, Acosta Y, Wang WH, Bonilla LR, Koutourousiou M, Wang E, et al: Endoscopic endonasal approach to the optic canal: anatomic considerations and surgical relevance. Neurosurgery 11 (Suppl 3):431-446, 2015

2. Bhatki AM, Carrau RL, Snyderman CH, Prevedello DM, 
Gardner PA, Kassam AB: Endonasal surgery of the ventral skull base-endoscopic transcranial surgery. Oral Maxillofac Surg Clin North Am 22:157-168, 2010

3. Colli BO, Carlotti CG Jr, Assirati JA Jr, Abud DG, Amato MC, Dezena RA: Results of microsurgical treatment of paraclinoid carotid aneurysms. Neurosurg Rev 36:99-115, 2013

4. Day AL: Aneurysms of the ophthalmic segment. A clinical and anatomical analysis. J Neurosurg 72:677-691, 1990

5. Di Somma A, de Notaris M, Stagno V, Serra L, Enseñat J, Alobid I, et al: Extended endoscopic endonasal approaches for cerebral aneurysms: anatomical, virtual reality and morphometric study. BioMed Res Int 2014:703792, 2014

6. Dumont AS, Crowley RW, Monteith SJ, Ilodigwe D, Kassell NF, Mayer S, et al: Endovascular treatment or neurosurgical clipping of ruptured intracranial aneurysms: effect on angiographic vasospasm, delayed ischemic neurological deficit, cerebral infarction, and clinical outcome. Stroke 41:25192524,2010

7. D'Urso PI, Karadeli HH, Kallmes DF, Cloft HJ, Lanzino G: Coiling for paraclinoid aneurysms: time to make way for flow diverters? AJNR Am J Neuroradiol 33:1470-1474, 2012

8. Durst CR, Starke RM, Gaughen J, Nguyen Q, Patrie J, Jensen ME, et al: Vision outcomes and major complications after endovascular coil embolization of ophthalmic segment aneurysms. AJNR Am J Neuroradiol 35:2140-2145, 2014

9. Eddleman CS, Batjer HH: Comment on "Germanwala AV, Zanation AM: Endoscopic endonasal approach for clipping of ruptured and unruptured paraclinoid cerebral aneurysms: case report." Neurosurgery $\mathbf{6 8}$ (Suppl):onsE240, 2011

10. Fernandez-Miranda JC, Tormenti M, Latorre F, Gardner P, Snyderman C: Endoscopic endonasal middle clinoidectomy: anatomic, radiological, and technical note. Neurosurgery 71 (2 Suppl Operative):ons233-ons239, 2012

11. Forbes JA, D' Herbemont S, Lehner KR, Pineda Martinez D, Navarro-Chávez IP, Mendez Rosito D, et al: Feasibility of endoscopic endonasal approach for clip application of cerebral aneurysms: a systematic review. J Neurosurg Sci [epub ahead of print], 2018

12. Gardner PA, Vaz-Guimaraes F, Jankowitz B, Koutourousiou M, Fernandez-Miranda JC, Wang EW, et al: Endoscopic endonasal clipping of intracranial aneurysms: surgical technique and results. World Neurosurg 84:1380-1393, 2015

13. Germanwala AV, Zanation AM: Endoscopic endonasal approach for clipping of ruptured and unruptured paraclinoid cerebral aneurysms: case report. Neurosurgery 68 (1 Suppl Operative):234-240, 2011

14. Heiferman DM, Somasundaram A, Alvarado AJ, Zanation AM, Pittman AL, Germanwala AV: The endonasal approach for treatment of cerebral aneurysms: a critical review of the literature. Clin Neurol Neurosurg 134:91-97, 2015

15. Jacquesson T, Abouaf L, Berhouma M, Jouanneau E: How I do it: the endoscopic endonasal optic nerve and orbital apex decompression. Acta Neurochir (Wien) 156:1891-1896, 2014

16. Joo W, Funaki T, Yoshioka F, Rhoton AL Jr: Microsurgical anatomy of the carotid cave. Neurosurgery 70 ( 2 Suppl Operative):300-312, 2012

17. Kallmes DF, Hanel R, Lopes D, Boccardi E, Bonafé A, Cekirge $S$, et al: International retrospective study of the pipeline embolization device: a multicenter aneurysm treatment study. AJNR Am J Neuroradiol 36:108-115, 2015

18. Kamide T, Tabani H, Safaee MM, Burkhardt JK, Lawton MT: Microsurgical clipping of ophthalmic artery aneurysms: surgical results and visual outcomes with 208 aneurysms. J Neurosurg [epub ahead of print January 26, 2018; DOI: 10.3171/2017.7.JNS17673]

19. Kassam A, Snyderman CH, Carrau RL, Gardner P, Mintz A: Endoneurosurgical hemostasis techniques: lessons learned from 400 cases. Neurosurg Focus 19(1):E7, 2005

20. Kassam AB, Gardner PA, Mintz A, Snyderman CH, Carrau RL, Horowitz M: Endoscopic endonasal clipping of an unse- cured superior hypophyseal artery aneurysm. Technical note. J Neurosurg 107:1047-1052, 2007

21. Kassam AB, Prevedello DM, Carrau RL, Snyderman CH, Gardner P, Osawa S, et al: The front door to Meckel's cave: an anteromedial corridor via expanded endoscopic endonasal approach-technical considerations and clinical series. Neurosurgery 64 (3 Suppl):ons71-ons83, 2009

22. Kassam AB, Thomas A, Carrau RL, Snyderman CH, Vescan A, Prevedello D, et al: Endoscopic reconstruction of the cranial base using a pedicled nasoseptal flap. Neurosurgery 63 (1 Suppl 1):ONS44-ONS53, 2008

23. Kassam AB, Vescan AD, Carrau RL, Prevedello DM, Gardner P, Mintz AH, et al: Expanded endonasal approach: vidian canal as a landmark to the petrous internal carotid artery. J Neurosurg 108:177-183, 2008

24. Kulwin C, Schwartz TH, Cohen-Gadol AA: Endoscopic extended transsphenoidal resection of tuberculum sellae meningiomas: nuances of neurosurgical technique. Neurosurg Focus 35(6):E6, 2013

25. Labib M, Dehdashti AR: Extended endoscopic endonasal transclival clipping of posterior circulation aneurysms - an alternative to the transcranial approach. Acta Neurochir (Wien) 157:2087-2088, 2015

26. Labib MA, Prevedello DM, Carrau R, Kerr EE, Naudy C, Abou Al-Shaar H, et al: A road map to the internal carotid artery in expanded endoscopic endonasal approaches to the ventral cranial base. Neurosurgery 10 (Suppl 3):448-471, 2014

27. Labib MA, Prevedello DM, Fernandez-Miranda JC, Sivakanthan S, Benet A, Morera V, et al: The medial opticocarotid recess: an anatomic study of an endoscopic "key landmark" for the ventral cranial base. Neurosurgery 72 (1 Suppl Operative): $66-76,2013$

28. Lai LT, Morgan MK, Snidvongs K, Chin DC, Sacks R, Harvey RJ: Endoscopic endonasal transplanum approach to the paraclinoid internal carotid artery. J Neurol Surg B Skull Base 74:386-392, 2013

29. Lin N, Brouillard AM, Keigher KM, Lopes DK, Binning MJ, Liebman KM, et al: Utilization of Pipeline embolization device for treatment of ruptured intracranial aneurysms: US multicenter experience. J Neurointerv Surg 7:808-815, 2015

30. Liu JK, Schmidt RF, Choudhry OJ, Shukla PA, Eloy JA: Surgical nuances for nasoseptal flap reconstruction of cranial base defects with high-flow cerebrospinal fluid leaks after endoscopic skull base surgery. Neurosurg Focus 32(6):E7, 2012

31. Pasqualin A, Meneghelli P, Cozzi F, Chioffi F: Outcome after surgical treatment of paraclinoid carotid aneurysms. Acta Neurochir Suppl 123:33-39, 2016

32. Peris-Celda M, Kucukyuruk B, Monroy-Sosa A, Funaki T, Valentine R, Rhoton AL Jr: The recesses of the sellar wall of the sphenoid sinus and their intracranial relationships. Neurosurgery 73 (2 Suppl Operative):ons117-ons131, 2013

33. Pribitkin EA, McJunkin J, Kung B, Carrasco JR, Bilyk JR, Savino PJ: Technique selection for orbital decompression: combined endoscopic and transconjunctival versus combined endoscopic and transantral approach. Ear Nose Throat J 88:E12, 2009

34. Rhoton AL Jr: The cavernous sinus, the cavernous venous plexus, and the carotid collar. Neurosurgery 51 (4 Suppl):S375-S410, 2002

35. Shimizu K, Imamura H, Mineharu Y, Adachi H, Sakai C, Sakai N: Endovascular treatment of unruptured paraclinoid aneurysms: single-center experience with 400 cases and literature review. AJNR Am J Neuroradiol 37:679-685, 2016

36. Silva MA, See AP, Dasenbrock HH, Patel NJ, Aziz-Sultan MA: Vision outcomes in patients with paraclinoid aneurysms treated with clipping, coiling, or flow diversion: a systematic review and meta-analysis. Neurosurg Focus 42(6):E15, 2017 
37. Srinivasan VM, Kan P, Germanwala AV, Pelargos P, Bohnen A, Choy W, et al: Key perspectives on Woven EndoBridge device for wide-necked bifurcation aneurysms, endoscopic endonasal clipping of intracranial aneurysms, retrosigmoid versus translabyrinthine approaches for acoustic neuromas, and impact of local intraoperative steroid administration on postoperative dysphagia following anterior cervical discectomy and fusion. Surg Neurol Int 7 (Suppl 27):S720-S724, 2016

38. Stieg P: Comment on "Germanwala AV, Zanation AM. Endoscopic endonasal approach for clipping of ruptured and unruptured paraclinoid cerebral aneurysms: case report." Neurosurgery 68 (Suppl 1):onsE240, 2011

39. Szentirmai O, Hong Y, Mascarenhas L, Salek AA, Stieg PE, Anand VK, et al: Endoscopic endonasal clip ligation of cerebral aneurysms: an anatomical feasibility study and future directions. J Neurosurg 124:463-468, 2016

40. Tayebi Meybodi A, Little AS, Vigo V, Benet A, Kakaizada S, Lawton MT: The pterygoclival ligament: a novel landmark for localization of the internal carotid artery during the endoscopic endonasal approach. J Neurosurg [epub ahead of print May 18, 2018; DOI: 10.3171/2017.12.JNS172435]

41. Valentine R, Wormald PJ: A vascular catastrophe during endonasal surgery: an endoscopic sheep model. Skull Base 21:109-114, 2011

42. Vaz-Guimaraes F, Gardner PA, Fernandez-Miranda JC, Wang E, Snyderman CH: Endoscopic endonasal skull base surgery for vascular lesions: a systematic review of the literature. J Neurosurg Sci 60:503-513, 2016

43. Wang Y, Li Y, Jiang C, Jiang F, Meng H, Siddiqui AH, et al: Endovascular treatment of paraclinoid aneurysms: 142 aneurysms in one centre. J Neurointerv Surg 5:552-556, 2013
44. Yadla S, Campbell PG, Grobelny B, Jallo J, Gonzalez LF, Rosenwasser RH, et al: Open and endovascular treatment of unruptured carotid-ophthalmic aneurysms: clinical and radiographic outcomes. Neurosurgery 68:1434-1443, 2011

45. Yilmazlar S, Saraydaroglu O, Korfali E: Anatomical aspects in the transsphenoidal-transethmoidal approach to the optic canal: an anatomic-cadaveric study. J Craniomaxillofac Surg 40:e198-e205, 2012

\section{Disclosures}

Dr. Little: ownership in SPIWay and Kogent.

\section{Author Contributions}

Conception and design: Preul, Tayebi Meybodi, Lawton. Acquisition of data: Tayebi Meybodi, Borba Moreira. Analysis and interpretation of data: Preul, Tayebi Meybodi, Borba Moreira, Little. Drafting the article: Tayebi Meybodi. Critically revising the article: all authors. Reviewed submitted version of manuscript: all authors. Approved the final version of the manuscript on behalf of all authors: Preul. Statistical analysis: Tayebi Meybodi, Borba Moreira. Administrative/technical/material support: Preul, Lawton. Study supervision: Preul, Lawton.

\section{Correspondence}

Mark C. Preul: Barrow Neurological Institute, St. Joseph's Hospital and Medical Center, Phoenix, AZ.mpreul@dignityhealth.org; neuropub@barrowneuro.org. 